\title{
Evidence about the use of Kinesio Taping in subjects with neurological disorders: an overview of systematic reviews
}

\author{
DOI: https://doi.org/10.5114/pq.2018.79740 \\ Paulo Roberto Fonseca Jr', Jessica Batista Nobre'2, Jahmerson Silva da Rocha ${ }^{1}$ \\ ${ }^{1}$ Irmandade da Santa Casa de Misericórdia de São Paulo, São Paulo, Brazil \\ ${ }^{2}$ Nove de Julho University, São Paulo, Brazil
}

\begin{abstract}
Introduction. To evaluate the evidence from published systematic reviews of clinical trials in order to determine the efficacy of Kinesio Taping in people with various neurological conditions.

Methods. The electronic databases of Cochrane Library, LILACS, MEDLINE, CINAHL, Embase, PubMed and PEDro were searched, with no restrictions regarding the date of publication or language. Systematic reviews/meta-analyses that evaluated the effectiveness of Kinesio Taping in subjects with neurological disorders up to $25^{\text {th }}$ January 2018 were included. Two reviewers applied the inclusion criteria for methodological quality with the use of a measurement tool to assess systematic reviews (AMSTAR).

Results. Overall, 5 systematic reviews were evaluated for evidence for the use of Kinesio Taping in subjects with neurological disorders. One review investigated effects of elastic therapeutic taping on motor function in children with motor impairments, 2 studies dealt with effects in children with cerebral palsy, and 2 systematic reviews concerned the effectiveness of Kinesio Taping in individuals with stroke. All studies presented a number of consequent improvements resulting from the elastic therapeutic taping, proving some of the goals proposed as a benefit of Kinesio Taping.

Conclusions. Although there are gaps in the literature with a range of Kinesio Taping techniques in use, the findings of this review suggest that recording may be effective when used in patients with neurological disorders. More research is needed to build evidence for protocol types, modalities, duration, and definition of the use of Kinesio Taping.

Key words: Kinesio Tape, nervous system diseases, therapy, review
\end{abstract}

\section{Introduction}

Several studies have emphasized the use of taping or neurotaping [1], such Kinesio Taping (KT), which is frequently applied in neurological rehabilitation clinics [2]. Over the past 20 years, numerous clinical studies have examined the use of adhesive taping as a therapeutic modality in individuals with neurological or musculoskeletal disorders [2-5]. Taping is an increasingly popular adjunct to therapy because it is uncomplicated to apply and inexpensive, and it can be easily removed or changed according to therapy objectives [2].

In neurological patients, KT has been used to correct postural misalignment, enhance the stability of joints, activate weak muscles, support weak structures, manage spasticity, stimulate mechanoreceptors, and increase sensory and proprioceptive feedback [6-8]. KT, also known as elastic therapeutic taping, neuromuscular, kinesthetic or kinesiology taping, is an adhesive tape applied directly to the surface of the skin $[8,9]$. The traction on the tape performed by the therapist promotes an elevation of the epidermis and reduces the pressure on the mechanoreceptors that are situated below the dermis, thus changing the recruitment activity patterns of the treated muscles. Other benefits have also been evaluated, such as joint realignment, blood flow and lymphatic circulation improvement, and reduction of pain intensity [9].

In recent years, various individual systematic reviews have investigated the effectiveness of KT in adult and paediatric populations with neurological conditions [2, 5, 6, 8]. These reviews, however, vary in quality, scope, and methodology, and at times report diverse findings. A systematic review of systematic reviews is a new approach to assemble current evidence across the same or very similar interventions in order to provide synthesis of treatment effects in a much broader context. The aim is to comprehensively synthesise evidence to establish benefit and harm associated with the interventions and guide the treatment $[10,11]$. This review, therefore, systematically evaluates evidence from published systematic reviews of clinical trials to determine the effectiveness of KT in people with various neurological conditions.

\section{Methods}

A comprehensive search of prominent health-science databases (MEDLINE, Cochrane Library, LILACS, PubMed, CINAHL, Embase, and PEDro) was undertaken for systematic reviews published until $25^{\text {th }}$ January 2018 that evaluated the effectiveness of KT in subjects with neurological disorders. Detailed search strategies used in each database are described in Appendix 1. Manual search of reference lists of potential articles and most relevant journals for additional references was conducted.

The study included systematic reviews/meta-analyses that evaluated the effectiveness of KT in subjects with neurological disorders, reported a systematic electronic search of literature for the defined period, referred to adult (> 18 years old) or infant/paediatric/teenager (0-17 years old) population, and were published in English. Also, systematic reviews/ meta-analyses investigating the effectiveness of KT as an

Correspondence address: Paulo Roberto Fonseca Jr, Irmandade da Santa Casa de Misericórdia de São Paulo, Dr. Cesário Mota Júnior, 112 - Vila Buarque, São Paulo, SP, Brazil, e-mail: paulofonseca28@gmail.com 
adjunct therapy were included. Excluded were reviews not performed among a population with neurological conditions, not evaluating the effect of KT, representing a low score in the measurement tool to assess systematic reviews (AMSTAR), lacking methodological clarity, not written in English, theses, narrative reviews, and reviews listed only in conference proceedings.

\section{Study selection and data extraction}

On the basis of the selection criteria, 2 authors (J.B.N. and J.S.R.) independently screened and shortlisted all abstracts and titles of reviews identified by the search strategy. Both authors autonomously evaluated each study abstract from the searched list, and full texts of all potential articles were obtained for assessment to determine whether the paper met the inclusion/exclusion criteria. Any disagreement regarding the possible inclusion/exclusion of any individual study was resolved by a discussion with the third author and by a final group consensus. The following data were extracted: publication and search date, objectives, characteristics of included studies and study subjects, intervention, findings, and limitations. Any discrepancies were resolved by all authors reviewing the study. When insufficient data were presented, the authors were contacted by e-mail and further data were requested.

\section{Assessment of the methodological quality} of included studies

The methodological quality of the included reviews was independently assessed with the AMSTAR appraisal tool by two reviewers who did not participate in the study and did not know its purpose [12]. AMSTAR, an 11-question tool (Appendix 2), is widely used in literature and has acceptable inter-rater agreement, construct validity, and feasibility [13]. Any discrepancies were resolved by a final consensus amongst all authors.

\section{Ethical approval}

The conducted research is not related to either human or animal use.

\section{Results}

The searches identified 639 published reviews. After screening the titles and removing duplicates, 434 reviews met abstract inclusion criteria and were selected for closer scrutiny. Full texts of these articles were retrieved and two reviewers (J.B.N. and J.S.R.) performed the final selection in accordance with the inclusion criteria. Overall, 5 systematic reviews were included. The discussion of the results of the included reviews referred to 3 neurological cohorts: children with motor impairments (1 review), children with cerebral palsy (2 reviews), and adults with stroke (2 reviews). A PRISMA diagram of the study selection process is provided in Figure 1.

\section{Quality of the systematic reviews}

Table 1 illustrates the results of the AMSTAR quality assessment. There was marked heterogeneity amongst the included reviews in terms of methodological quality and risk of bias in the assessment methods. Two reviews were excluded as lacking clarity of methodological procedures and reporting, and did not follow the PRISMA guidelines [14, 15], obtaining an extremely low score (0 and 1$)$ in AMSTAR. The overall mean AMSTAR methodological quality score for the included systematic reviews was 7.6 and ranged from 5 to 9 out of 11 . The quality of the included systematic reviews was considered good: 3 reviews were of high quality (i.e. AMSTAR scores 9) $[2,5,8]$ and 2 represented moderate quality $(5,6)[16,17]$.

All reviews involved comprehensive literature searches of medical science databases; however, only half of them provided a grey literature search. All included reviews had published a priori protocols or lists of excluded studies. All
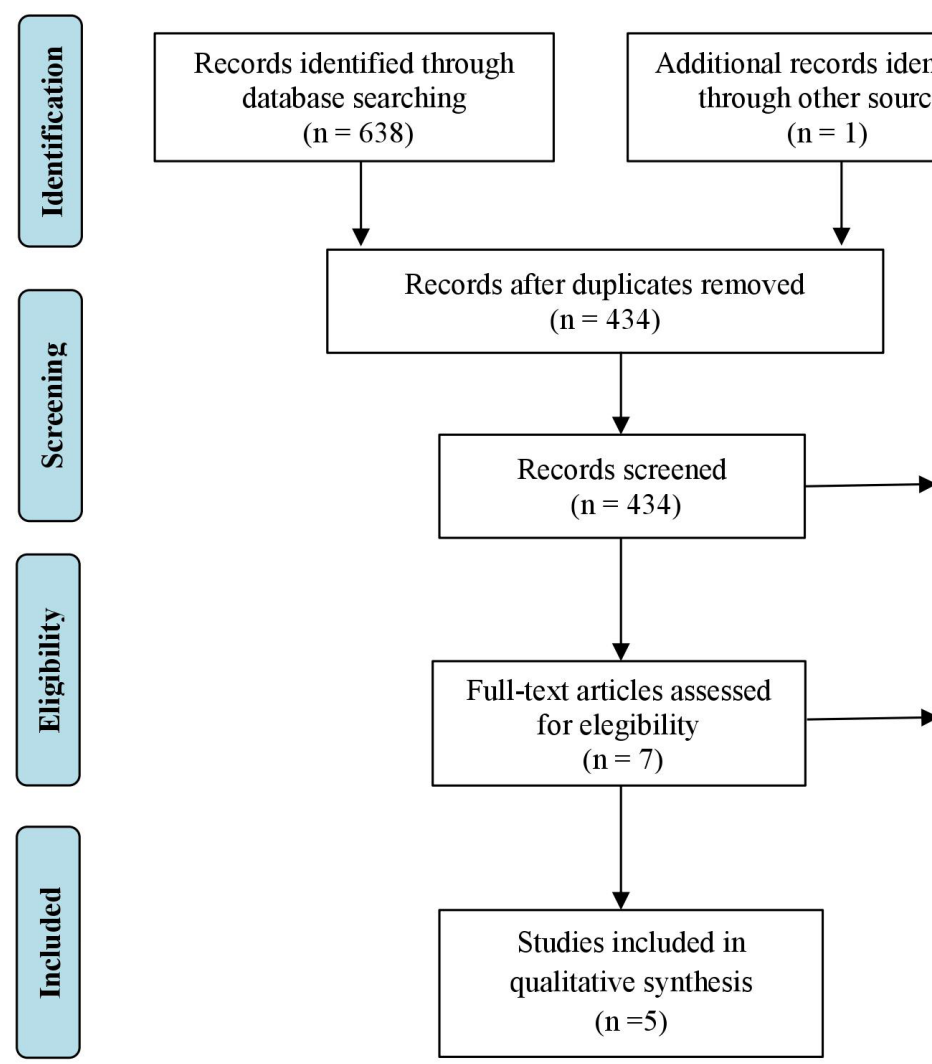

Records excluded $(n=427)$

Full-text articles excluded, with reasons $(\mathrm{n}=2)$

Extremely low AMSTAR score: 2

Studies included in $(n=5)$ 
Table 1. Quality assessment (AMSTAR) of the included systematic reviews

AMSTAR criteria

\begin{tabular}{|l|c|c|c|c|c|c|c|c|c|c|c|c|}
\hline Authors, year & 1 & 2 & 3 & 4 & 5 & 6 & 7 & 8 & 9 & 10 & 11 & Total \\
\hline Cunha et al., 2018 [8] & $\mathrm{Y}$ & $\mathrm{Y}$ & $\mathrm{Y}$ & $\mathrm{Y}$ & $\mathrm{Y}$ & $\mathrm{Y}$ & $\mathrm{Y}$ & $\mathrm{Y}$ & $\mathrm{N}$ & $\mathrm{N}$ & $\mathrm{Y}$ & 9 \\
\hline Grampurohit et al., 2015 [5] & $\mathrm{Y}$ & $\mathrm{Y}$ & $\mathrm{Y}$ & $\mathrm{Y}$ & $\mathrm{Y}$ & $\mathrm{Y}$ & $\mathrm{Y}$ & $\mathrm{Y}$ & $\mathrm{N}$ & $\mathrm{N}$ & $\mathrm{Y}$ & 9 \\
\hline Güçhan and Mutlu, 2017 [2] & $\mathrm{Y}$ & $\mathrm{Y}$ & $\mathrm{Y}$ & $\mathrm{Y}$ & $\mathrm{Y}$ & $\mathrm{Y}$ & $\mathrm{Y}$ & $\mathrm{Y}$ & $\mathrm{N}$ & $\mathrm{N}$ & $\mathrm{Y}$ & 9 \\
\hline Ortiz-Ramírez and Pérez-De la Cruz, 2017 [16] & $\mathrm{Y}$ & $\mathrm{N}$ & $\mathrm{Y}$ & $\mathrm{Y}$ & $\mathrm{N}$ & $\mathrm{Y}$ & $\mathrm{Y}$ & $\mathrm{N}$ & $\mathrm{N}$ & $\mathrm{N}$ & $\mathrm{N}$ & 5 \\
\hline Shamsoddini et al., 2016 [17] & $\mathrm{Y}$ & $\mathrm{N}$ & $\mathrm{Y}$ & $\mathrm{Y}$ & $\mathrm{Y}$ & $\mathrm{Y}$ & $\mathrm{N}$ & $\mathrm{N}$ & $\mathrm{N}$ & $\mathrm{N}$ & $\mathrm{Y}$ & 6 \\
\hline
\end{tabular}

AMSTAR - a measurement tool to assess systematic reviews (for the specific criteria refer to Appendix 2), $Y$ - yes, criteria met (1 point), $\mathrm{N}-$ no, criteria not met (0 points)

reviews, except $2[16,17]$, assessed the scientific quality of the included primary studies using various tools: Grampurohit et al. [5] used the PEDro rating system [18] and CONSORT statement guidelines [19]. The reason for further evaluation of randomized controlled trials (RCTs) applying CONSORT was the additional criteria regarding randomization specific to RCTs. The 2 rating scales provided an estimate of bias risk in the studies [5]. Cunha et al. [8] used an appropriate checklist for any clinical trial. The checklist contained 27 items, subdivided into 5 sections (reporting, external validity, internal validity - bias and confounding, and power) [20]. Güçhan and Mutlu [2] applied the critical review guidelines of McMaster University and Sackett's levels of evidence, created by Dr David Sackett from the Faculty of Health Sciences, McMaster University [21]. All reviews, except 1 [16], provided their funding sources and addressed the potential competing interests of authors of the primary studies (Table 1).

\section{Evidence synthesis of the use of KT in subjects with neurological disorders}

The existing best-evidence syntheses for KT application in subjects with neurological disorders are summarized below and in Table 2.

\section{Motor impairments}

One review investigated effects of elastic therapeutic taping on motor function in children with motor impairments aged from 1.7 months to 16 years [8]. The findings were homogeneous. The final selection was composed of 12 manuscripts, referring to children with cerebral palsy as the most recurrent disorder $(n=8)$, followed by congenital muscular torticollis $(n=2)$ and brachial plexus palsy $(n=2)$.

In 8 of the 12 included studies (66\%), the children received conventional physical therapy associated with elastic therapeutic taping, showing to be a promising adjunct resource to the conventional rehabilitation of motor impairments. Among the 12 studies included, 11 presented a number of consequent improvements resulting from the elastic therapeutic taping use, such as: improvement in the upper limb function, gross motor skills, postural control, muscular balance, and performance in the functional dynamics and daily activities. The experimental conditions were varied, with some studies reporting short-term effects, after 3 days of taping usage, and others focusing on long-term effects, observed after an intervention period of 4-12 weeks.

\section{Cerebral palsy}

Two reviews investigated effects only in children with cerebral palsy aged $1-14$ years $[2,17]$. The topographical classification was mixed, including spastic, hemiplegic, diplegic, and quadriplegic cerebral palsy. In the systematic review by Güçhan and Mutlu [2], the included studies covered all the gross motor function classification system (GMFCS) levels [22], and the tapes were grouped as elastic and rigid. Seven papers described the usage of elastic tapes only, 1 - rigid tapes, and 1 - both rigid and elastic tapes. Elastic tapes were more frequently applied in practice because they did not limit the children's movement as much as inelastic ones. However, the effectiveness of taping in paediatric neurological conditions was not discussed. The children varied in the GMFCS levels, but the authors investigating the effects of upper limb taping did not present any information about the level of hand ability in the included children. Of the 9 included articles, only 3 presented significant improvements and functional gains after taping. In turn, no significant change was shown in 4 studies.

Shamsoddini et al. [17] report that KT can be used in rehabilitation in combination with other common therapeutic techniques, including: increase of strength, enhancement of endurance, improving the range of motion, and reduction of spasticity. Bearing in mind the results of the included studies, the reviewers concluded that the KT technique favourably impacted on the fine and gross motor abilities and functional independence in activities of daily living, sitting/standing control, and balance, through sensory stimulation and promotion of function. However, still based on the outcomes of the included studies, KT turned out more effective in mild to moderate cerebral palsy and was not effective in severe cases.

\section{Stroke}

Two systematic reviews evaluated KT effectiveness in adults with stroke (age not specified) [5, 16]. In a systematic review, Grampurohit et al. [5] assessed the efficacy of adhesive taping as an adjunct to physical rehabilitation, obtaining preliminary evidence in the domain of body structure and function for the use of rigid tape at the shoulder to increase the number of pain-free days post-stroke. However, the evidence was inconclusive for the improvement of pain intensity, range of motion, muscle tone, or strength with taping. The overall quality of the available evidence is modest.

In the results of the review carried out by Ortiz-Ramírez and Pérez-De la Cruz [16], 3 studies performed on the efficacy of KT in improving balance in stroke patients found 
Table 2. Characteristics of the included systematic reviews

\begin{tabular}{|c|c|c|c|c|c|}
\hline Authors, year & Participants & Body part taped & $\begin{array}{l}\text { Number } \\
\text { of included } \\
\text { studies }\end{array}$ & $\begin{array}{l}\text { Total number } \\
\text { of } \\
\text { participants }\end{array}$ & Main findings \\
\hline $\begin{array}{l}\text { Cunha et al., } \\
2018 \text { [8] }\end{array}$ & $\begin{array}{l}\text { Children ( } 1.7 \text { months } \\
\text { to } 16 \text { years) with acquired } \\
\text { disorders of upper limb, } \\
\text { CP (spastic hemiplegia), } \\
\text { congenital muscular torticollis, } \\
\text { unilateral obstetric brachial } \\
\text { plexus palsy, muscular } \\
\text { imbalance, flexors of the } \\
\text { neck } \\
\text { disorders }\end{array}$ & $\begin{array}{l}\text { Upper limb, paraspinal muscu- } \\
\text { lature, sternocleidomastoid } \\
\text { and superior trapezius muscles, } \\
\text { quadriceps and anterior tibial } \\
\text { muscles, deltoid and biceps } \\
\text { muscles, knee joint, } \\
\text { for scapular stabilization } \\
\text { and forearm supination, thumb } \\
\text { opponency, acromioclavicular } \\
\text { joint to T12, middle and lower } \\
\text { trapezius muscles }\end{array}$ & $\begin{array}{l}5 \text { RCTs } \\
3 \text { CTs (pilot study) } \\
2 \text { CTs (quasi- } \\
\text {-randomized) } \\
1 \text { CT (retrospective) } \\
1 \text { CT } \\
\text { Search date: till } \\
\text { November } 2016\end{array}$ & 328 & $\begin{array}{l}\text { Beneficial results obtained } \\
\text { in muscle activation and relaxation, } \\
\text { control of sitting posture, upper } \\
\text { limb function, and performance } \\
\text { in dynamic and functional activities } \\
\text { of daily living, with increased } \\
\text { functional independence }\end{array}$ \\
\hline $\begin{array}{l}\text { Grampurohit } \\
\text { et al., } 2015 \text { [5] }\end{array}$ & $\begin{array}{l}\text { Post-stroke patients } \\
\text { (age not specified) }\end{array}$ & $\begin{array}{l}\text { Shoulder, wrist and hand, } \\
\text { ankle, knee, hip }\end{array}$ & $\begin{array}{l}12 \text { RCTs } \\
2 \text { case studies } \\
1 \text { cohort study } \\
\text { Search date: } \\
\text { till December } 2013\end{array}$ & 444 & $\begin{array}{l}\text { Preliminary evidence in the body } \\
\text { function and structure domain } \\
\text { to suggest that the use of a rigid } \\
\text { adhesive tape at the shoulder as } \\
\text { an adjunct treatment may increase } \\
\text { the number of pain-free days. } \\
\text { Inconclusive evidence that taping } \\
\text { post-stroke improves other aspects } \\
\text { of body function and structure, } \\
\text { including pain intensity, range } \\
\text { of motion, muscle tone, strength }\end{array}$ \\
\hline $\begin{array}{l}\text { Güçhan } \\
\text { and Mutlu, } \\
2017 \text { [2] }\end{array}$ & $\begin{array}{l}\text { CP: spastic hemiplegic, } \\
\text { diplegic, hemiparetic, } \\
\text { and quadriparetic } \\
\text { (age, 1-17 years) }\end{array}$ & $\begin{array}{l}\text { Ankle, femoris and tibialis } \\
\text { anterior muscles, calf muscles, } \\
\text { paraspinal muscles }\end{array}$ & $\begin{array}{l}5 \text { RCTs } \\
3 \text { case series } \\
1 \text { case study } \\
\text { Search date: } \\
\text { till May } 2015\end{array}$ & 191 & $\begin{array}{l}\text { Significant improvements after } \\
\text { taping only in } 3 \text { studies, concerning } \\
\text { upper limb function and functional, } \\
\text { stable, and symmetric locomotor } \\
\text { patterns }\end{array}$ \\
\hline $\begin{array}{l}\text { Ortiz-Ramírez } \\
\text { and Pérez- } \\
\text {-De la Cruz, } \\
2017 \text { [16] }\end{array}$ & Stroke (age not specified) & $\begin{array}{l}\text { Shoulder, fibular and tibialis } \\
\text { anterior muscles, medial and } \\
\text { lateral heads of gastrocnemius } \\
\text { muscle, external laryngeal } \\
\text { muscles, sternocleidomastoid } \\
\text { and the upper trapezius, knee } \\
\text { joint }\end{array}$ & $\begin{array}{l}1 \text { CT (pilot study) } \\
5 \text { RCTs } \\
2 \text { CTs }\end{array}$ & 193 & $\begin{array}{l}\text { Significant changes in the balance, } \\
\text { speed, and range of movements } \\
\text { in the upper limb affected. } \\
\text { Functional dysphagia scale found } \\
\text { good results with taping }\end{array}$ \\
\hline $\begin{array}{l}\text { Shamsoddini } \\
\text { et al., } 2016 \\
{[17]}\end{array}$ & $\begin{array}{l}\text { CP: spastic hemiplegic, } \\
\text { diplegic, hemiparetic, } \\
\text { and quadriparetic } \\
\text { (age, 3-14 years) }\end{array}$ & $\begin{array}{l}\text { Lateral epicondyle, extensor } \\
\text { surface of the thumb, extensor } \\
\text { muscle of wrist, palmar, cervical, } \\
\text { anterior, and posterior region } \\
\text { of shoulder, forearm (for supina- } \\
\text { tion), erector spine muscles, } \\
\text { ankle, knee, hip, quadriceps } \\
\text { and tibialis anterior }\end{array}$ & $\begin{array}{l}8 \text { RCTs } \\
2 \text { CTs (quasi- } \\
\text {-randomized) } \\
4 \text { CTs (pilot study) } \\
4 \text { CTs } \\
2 \text { case studies } \\
1 \text { review }\end{array}$ & 328 & $\begin{array}{l}\text { The majority of consistent findings } \\
\text { showing that KT as part of a multi- } \\
\text { modal therapy program can be effec- } \\
\text { tive in the rehabilitation of children } \\
\text { with CP to improve gross and fine } \\
\text { motor function and dynamic activities, } \\
\text { especially in higher developmental } \\
\text { and motor stages }\end{array}$ \\
\hline
\end{tabular}

CP - cerebral palsy, RCT - randomized controlled trial, CT - controlled trial, KT - Kinesio Taping

significant differences in their outcomes of applying KT associated with other therapeutic techniques, considered a good tool in the treatment of balance disorders among patients who had undergone a stroke. Two studies found an improvement in the range of motion and functionality, and changes in the speed at which the affected upper limb movements were performed. One study describing KT in the treatment of dysphagia proved good results as evaluated by a functional dysphagia scale, kinematic analysis of the hyoid bone, and a videofluoroscope study. There were no significant differences in hemiplegic shoulder pain in patients with stroke.

\section{Discussion}

Since the popularity of taping in rehabilitation clinics has gradually increased [23], the purpose of this overview was to analyse evidence from published systematic reviews to date for the use of KT in subjects with neurological disorders. Overall, 5 systematic reviews were evaluated for outcome data specific to KT. The findings indicate that, though a broad range of KT approaches are trialled for different neurological cohorts, high-quality evidence for the effectiveness of these modalities is limited.

The methodological quality and evidence in the systematic reviews had little variation, as shown by the range of the AMSTAR scores. Overall, more than half of the included reviews were of high methodological quality. None presented test results to assess the homogeneity of the study findings or a random effects model when there were heterogeneous findings to ensure the studies were combinable. Also, none of the reviews involved an assessment of publication bias including a combination of graphical aids. 
Therefore, none fulfilled the $9^{\text {th }}$ and $10^{\text {th }}$ criteria of the AMSTAR tool (Appendix 2). In the majority of the included reviews, different tools were applied to evaluate the methodological quality of the included studies. Only 2 reviews did not assess the quality of the included studies.

Although there are more applications of KT in musculoskeletal practice, the current evidence in the literature does not support the use of this intervention in these clinical populations [24]. Numerous clinical studies have examined the application of adhesive taping as a therapeutic modality in individuals post-stroke $[25,26]$ and in children with cerebral palsy [2]. However, despite a large scale adherence in the treatment of neurological disorders in both adults and children, systematic reviews on KT effectiveness in these populations still present conflicting results [2, 5, 8, 16, 17].

All studies presented a number of consequent improvements resulting from elastic therapeutic taping. For example, in the review by Cunha et al. [8], the findings concerning effects of elastic therapeutic taping on motor function in children with motor impairments were homogeneous and included improvement in the upper limb function, gross motor skills, postural control, muscular balance, and performance in the functional dynamics and daily activities. Two reviews that investigated effects of KT in children with cerebral palsy $[2,17]$ reported significant improvements and functional gains after taping; these referred to fine and gross motor abilities and functional independence in activities of daily living, sitting/standing control and balance. The conclusion was that KT could be performed in cerebral palsy children of different functional and topographic levels. In addition, children are more participative when they use elastic tapes instead of rigid ones [2]. In patients with stroke, the results are mixed. Two reviews $[5,16]$ proved that KT could be effective to improve the body structure and function. However, the evidences are contradictory for the improvement of pain and range of motion with taping.

\section{Limitations}

There are a number of limitations that should be considered when interpreting the results of this review of literature. First, given the relatively small number of systematic reviews published in this area, the evidence is still scarce, making it difficult to suggest strong recommendations about the effects of KT in subjects with neurological disorders. Second, the reviews included in this study are accompanied with specific difficulties: a small number of randomized controlled clinical trials (recommended for evaluating the highest degree of evidence in systematic reviews), little comprehensiveness of KT interventions in other neurological diseases, heterogeneity of the evaluated conditions and of the methodological procedures used $[2,5,8,16,17]$.

\section{Conclusions}

There is increasing awareness of the contribution of KT in subjects with neurological disorders. Despite the range of KT techniques in use, evidence for many is still unclear. Although there are gaps in literature, the findings from this review suggest that the taping may be effective, e.g. in improving the body structure, upper limb function, functional dynamics, and daily activities. More research is needed to build evidence with regard to types of protocols, modalities, duration, and settings of the use of KT.

\section{Disclosure statement}

No author has any financial interest or received any financial benefit from this research.

\section{Conflict of interest}

The authors state no conflict of interest. No commercial party having a direct financial interest in the results of the research supporting this article has conferred or will confer a benefit upon the authors or upon any organization with which the authors are associated.

\section{References}

1. Griffin C. Management of the hemiplegic shoulder complex. Top Stroke Rehabil. 2014;21(4):316-318; doi: 10.1310/tsr2104-316.

2. Güçhan Z, Mutlu A. The effectiveness of taping on children with cerebral palsy: a systematic review. Dev Med Child Neurol. 2017;59(1):26-30; doi: 10.1111/dmcn.13213.

3. Lim EC, Tay MG. Kinesio taping in musculoskeletal pain and disability that lasts for more than 4 weeks: is it time to peel off the tape and throw it out with the sweat? A systematic review with meta-analysis focused on pain and also methods of tape application. Br J Sports Med. 2015;49(24):1558-1566; doi: 10.1136/bjsports-2014094151.

4. Csapo R, Alegre LM. Effects of Kinesio ${ }^{\circledR}$ taping on skeletal muscle strength - a meta-analysis of current evidence. J Sci Med Sport. 2015;18(4):450-456; doi: 10.1016/j.jsams.2014.06.014.

5. Grampurohit N, Pradhan S, Kartin D. Efficacy of adhesive taping as an adjunt to physical rehabilitation to influence outcomes post-stroke: a systematic review. Top Stroke Rehabil. 2015;22(1):72-82; doi: 10.1179/10749 35714Z.0000000031.

6. Jaraczewska E, Long C. Kinesio taping in stroke: improving functional use of the upper extremity in hemiplegia. Top Stroke Rehabil. 2006;13(3):31-42; doi: 10.1310/33KA-XYE3-QWJB-WGT6.

7. Morris D, Jones D, Ryan H, Ryan CG. The clinical effects of Kinesio ${ }^{\circledR}$ Tex taping: a systematic review. Physiother Theory Pract. 2013;29(4):259-270; doi: 10.3109/0959 3985.2012.731675.

8. Cunha AB, Lima-Alvarez CD, Rocha ACP, Tudella E. Effects of elastic therapeutic taping on motor function in children with motor impairments: a systematic review. Disabil Rehabil. 2018;40(14)1609-1617; doi: 10.1080/ 09638288.2017 .1304581$.

9. Kase K, Wallis J, Kase T. Clinical therapeutic applications of the Kinesio Taping method. Tokyo: Kení-kai Co., Ltd.; 2003.

10. Smith V, Devane D, Begley CM, Clarke M. Methodology in conducting a systematic review of systematic reviews of healthcare interventions. BMC Med Res Methodol. 2011;11(1):15; doi: 10.1186/1471-2288-11-15.

11. Khan F, Amatya B, Bensmail D, Yelnik A. Non-pharmacological interventions for spasticity in adults: an overview of systematic reviews. Ann Phys Rehabil Med. 2017; doi: 10.1016/j.rehab.2017.10.001.

12. Shea BJ, Grimshaw JM, Wells GA, Boers M, Andersson N, Hamel C, et al. Development of AMSTAR: a measurement tool to assess the methodological quality of systematic reviews. BMC Med Res Methodol. 2007;7:10; doi: 10.1186/1471-2288-7-10.

13. Shea BJ, Bouter LM, Peterson J, Boers M, Andersson N, Ortiz Z, et al. External validation of a measurement tool 
to assess systematic reviews (AMSTAR). PLoS One. 2007;2(12):e1350; doi: 10.1371/journal.pone.0001350.

14. Moher D, Liberati A, Tetzlaff J, Altman DG, The PRISMA Group. Preferred reporting items for systematic reviews and meta-analyses: the PRISMA statement. BMJ. 2009; 339:b2535; doi: 10.1136/bmj.b2535.

15. Liberati A, Altman DG, Tetzlaff J, Mulrow C, Gøtzsche PC, Ioannidis JP, et al. The PRISMA statement for reporting systematic reviews and meta-analyses of studies that evaluate health care interventions: explanation and elaboration. PLoS Med. 2009;6(7):e1000100; doi: 10.1371/ journal.pmed. 1000100 .

16. Ortiz-Ramírez J, Pérez-De la Cruz S. Efficacy of the application of kinesio tape in patients with stroke [in Spanish]. Rev Neurol. 2017;64(4):175-179.

17. Shamsoddini A, Rasti Z, Kalantari M, Hollisaz MT, Sobhani $\mathrm{V}$, Dalvand $\mathrm{H}$, et al. The impact of Kinesio taping technique on children with cerebral palsy. Iran J Neurol. 2016;15(4):219-227.

18. Shiwa SR, Costa LOP, Moser ADL, Aguiar IC, Oliveira LVF. PEDro: the physiotherapy evidence database [in Portuguese]. Fisioter Mov. 2011;24(3):523-533; 10.1590/ S0103-51502011000300017.

19. Moher D, Hopewell S, Schulz KF, Montori V, Gøtzsche PC, Devereaux PJ, et al. CONSORT 2010 explanation and elaboration: updated guidelines for reporting parallel group randomised trials. Int J Surg. 2012;10(1):2855; doi: 10.1016/j.ijsu.2011.10.001.

20. Downs S, Black N. The feasibility of creating a checklist for the assessment of the methodological quality both of randomised and non-randomised studies of health care interventions. J Epidemiol Community Health. 1998; 52(6):377-384; doi: 10.1136/jech.52.6.377.

21. Sur RL, Dahm P. History of evidence-based medicine. Indian J Urol. 2011;27(4):487-489; doi: 10.4103/09701591.91438.

22. Palisano R, Rosenbaum P, Walter S, Russell D, Wood E, Galuppi B. Development and reliability of a system to classify gross motor function in children with cerebral palsy. Dev Med Child Neurol. 1997;39(4):214-223; doi: 10.1111/dmcn.1997.39.issue-4.

23. Kara OK, Uysal SA, Turker D, Karayazgan S, Gunel MK, Baltaci G. The effects of Kinesio Taping on body functions and activity in unilateral spastic cerebral palsy: a single-blind randomized controlled trial. Dev Med Child Neurol. 2015;57(1):81-88; doi: 10.1111/dmcn.12583.

24. Parreira PCS, Costa LCM, Hespanhol LC jr, Lopes AD, Costa LOP. Current evidence does not support the use of Kinesio Taping in clinical practice: a systematic review. J Physiother. 2014;60(1):31-39; doi: 10.1016/j. jphys.2013.12.008.

25. Pandian JD, Kaur P, Arora R, Vishwambaran DK, Toor G, Mathangi S, et al. Shoulder taping reduces injury and pain in stroke patients: randomized controlled trial. Neurology. 2013;80(6):528-532; doi: 10.1212/WNL.0b013e 318281550e.

26. Hanger HC, Whitewood P, Brown G, Ball MC, Harper J, Cox $\mathrm{R}$, et al. A randomized controlled trial of strapping to prevent post-stroke shoulder pain. Clin Rehabil. 2000; 14(4):370-380; doi: 10.1191/0269215500cr339oa.

\section{Appendix 1. Search strategies}

MEDLINE and PubMed:

1 kinesiotaping

2 kinesio taping

3 kinesiotape

4 kinesio tape

5 Systematic review/

6 Review/

7 Review literature as topic //

8 or/5-7

Embase:

1 kinesiotaping

2 kinesio taping

3 kinesiotape

4 kinesio tape

5 or/1-4

6 Systematic review/

7 Review/

8 Review literature as topic //

9 or/6-8

CINAHL:

S1 kinesiotaping

S2 kinesio taping

S3 kinesiotape

S4 kinesio tape

$\mathrm{S} 5 \mathrm{~S} 1$ or S2 or S3 or S4

S6 (MH "Systematic Review+")

S7 "systematic review *"

S8 review

S9 $\mathrm{S} 6$ or $\mathrm{S} 7$ or S8

PEDro:

1 kinesiotaping

2 kinesio taping

3 kinesiotape

4 kinesio tape

* search strategy was performed for each term at a time, with the option "clinical trial" checked

\section{LILACS:}

1 kinesiotaping

2 kinesio taping

3 "kinesio" "taping"

4 kinesiotape

5 kinesio tape

6 "kinesio" "tape"

71 OR 2 OR 3 OR 4 OR 5 OR 6

Cochrane Library:

1 kinesiotaping

2 kinesio taping

3 "kinesio" "taping"

4 kinesiotape

5 kinesio tape

6 "kinesio" "tape"

71 OR 2 OR 3 OR 4 OR 5 OR 6

\section{Appendix 2. A measurement tool to assess systematic reviews (AMSTAR): criteria}

1. Was an a priori design provided?

2. Were there duplicate study selection and data extraction?

3. Was a comprehensive literature search performed? 
4. Was the status of publication (i.e. grey literature) used as an inclusion criterion?

5. Was a list of studies (included and excluded) provided?

6 . Were the characteristics of the included studies provided?

7. Was the scientific quality of the included studies assessed and documented?

8. Was the scientific quality of the included studies used appropriately in formulating conclusions?

9. Were the methods used to combine the findings of studies appropriate?

10. Was the likelihood of publication bias assessed?

11. Was the conflict of interest stated?

Each AMSTAR criterion is scored as:

$\mathrm{Y}$ - yes, criteria met

$\mathrm{N}$ - no, criteria not met

UA - unable to answer

NA - not applicable 